\title{
Serum Kidney Injury Molecule-1 in Hepatorenal Syndrome at Medical Intensive Care Unit of Zagazig University Hospitals
}

\author{
Usama Khalil $^{1}$, Fayroz O Seliem ${ }^{2}$, Ashraf Khalifa ${ }^{3}$, Ayman M.E.M. Sadek ${ }^{4}$, Mohammad S. Fawzi ${ }^{5}$ Nermin Raafat $^{6}$ \\ ${ }^{12,3,4}$ Internal Medicine Department, faculty of Medicine, Zagazig University, Egypt \\ ${ }^{5,6}$ Medical Biochemistry Departments, faculty of Medicine, Zagazig University, Egypt
}

\begin{abstract}
Background: Criteria of international club of ascites (IAC), 2007 for diagnosis of hepatorenal syndrome (HRS) did not rule out the possibility of renal parenchymal damage. Biomarkers of renal tubular damage especially kidney injury molecule-1 (KIM-1) has a potential role in differentiating types of acute kidney injury (AKI). Aim: This study aimed at measuring serum KIM-1 in HRS patients to assess; sufficiency of IAC criteria 2007 to exclude intrinsic kidney injury, evaluate percentage of intrinsic kidney injury, and test the relation of serum KIM-1 to kidney functions in HRS patients. Methods: 98 HRS patients according to IAC criteria (2007) admitted to medical ICU within 10 months were included and classified into type1 and type 2 according to the level and rising pattern of serum creatinine.Complete blood picture, liver and kidney function tests, bleeding profile, arterial blood gases, pelvi-abdominal ultrasonography; and serum KIM-1 were evaluated. Results: $73.5 \%$ of HRS patients had type1 and $26.5 \%$ had type2. The cutoff value of serum KIM-1 for severity of AKI in HRS is $3.69 \mathrm{ng} / \mathrm{ml}$ (88.6\%sensitivity, 76.9\% specificity and 0.81\%AUC). Percentage of intrinsic kidney injury was $76.1 \%$ in type1 and $24.9 \%$ in type 2 . There was significant positive correlation between serum KIM-1 and urine protein $(r=0.45, P=0.005)$, serum creatinine $(r=0.42, P=0.006)$ and Child-Pugh score and negative correlation with estimated glomerular filtration rate $(r=-0.91, P=0.01)$. Conclusion: Serum KIM-1 may be considered as a valid marker for prediction of intrinsic kidney injury among patients with HRS and classify them as type3.
\end{abstract}

Keywords: hepatorenal syndrome, acute kidney injury, kidney injury molecule-1

\section{Introduction}

Hepatorenal syndrome is a unique type of kidney failure that occurs in advanced liver cirrhosis. It is characterized by functional impairment of the kidneys due to vasoconstriction of the renal arteries in the setting of preserved tubular function and absence of significant histological abnormalities(1).

Two different clinical types of HRS have been described; type1 (acute form of kidney injury) with doubling of serum creatinine reaching a level greater than $2.5 \mathrm{mg} / \mathrm{dl}$ in less than 2 weeks,type2 (subacute form of kidney injury) with moderate and slowly progressive renal failure (serum creatinine lower than $2.5 \mathrm{mg} / \mathrm{dl})(2)$.

International Ascites Club (IAC) 2007 has provided diagnostic criteria for HRS as; cirrhosis with ascites and serum creatinine more than $1.5 \mathrm{mg} / \mathrm{dl}$ with no improvement of serum creatinine (decrease to a level $\leq 1.5 \mathrm{mg} / \mathrm{dl}$ ) after at least two days of diuretic withdrawal and volume expansion with albumin. The recommended dose of albumin is $1 \mathrm{~g} / \mathrm{kg}$ of body weight per day up to a maximum of $100 \mathrm{~g} /$ day in absence of shock or current or recent treatment with nephrotoxic drugs and absence of parenchymal kidney disease as indicated by proteinuria $>500 \mathrm{mg} /$ day, microhematuria ( $>50$ red blood cells per high power field), and/or abnormal renal ultrasonography (3).

The last classification of the HRS was done by Munozas the following; type1: cirrhosis with rapidly progressive acute renal failure, type 2: cirrhosis with subacute renal failure, type 3 : cirrhosis with types 1 or 2 HRS superimposed on chronic kidney disease or acute renal injury and type 4 : fulminant liver failure with HRS (4).

Patients who fulfill the diagnostic criteria of HRS according to IAC, 2007 may still have structural damage such as tubular damage. Serum and urine biomarkersbecome an important element in making a more accurate differential diagnosis between HRS and acute tubular necrosis (5).

Serum creatinine levels or estimated glomerular filtration rate (eGFR), as well as urinary output, are the most commonly used markers of renal function and are used to determine the magnitude of renal injury. It must be recognized, however, that such markers are imperfect. They cannot be used to distinguish between hemodynamically mediated changes in renal function, such as pre-renal azotemia as opposed to intrinsic renal failure or obstructive uropathy. Similarly, changes in volume states can significantly influence the levels of serum creatinine, further minimizing the true relative change in renal function. Furthermore, there may be a significant time lag (in hours or days) between the change in the above markers and the actual onset of anatomic or structural damage (6).

Knowing the above limitations of currently used kidney function markers, it is accepted that they may be unable to detect any acute injury or process; in fact, their levels may rise coincident with a late period in the injury process. This has led researchers to find more accurate kidney function biomarkers (serum and/or urine)(7).

A working party proposal suggested defining AKI in cirrhotic patients as a rise in serum creatinine by $0.3 \mathrm{mg} / \mathrm{dl}$ or 


\section{International Journal of Science and Research (IJSR) \\ ISSN (Online): 2319-7064}

Index Copernicus Value (2013): 6.14 | Impact Factor (2015): 6.391

more within a 48 -hour period or an absolute $50 \%$ rise in serum creatinine (8).

Novel biomarkers are proteins that are expressed in response to kidney injury, predominantly by tubular injury. These markers may be classified as; tubular epithelial cell enzymes released into the urine after cellular stress or injury, inflammatory mediators or cytokines released by kidney specific cells or by infiltrating inflammatory cells during AKI, and low molecular weight proteins, which are filtered freely in the glomerulus and then not adequately digested and reabsorbed by damaged tubular cells (9).

Such biomarkers accumulate in urine due to an induced tubular epithelial synthesis in different parts of the nephron like; kidney injury molecule-1 (KIM-1), neutrophil gelatinase-associated lipocalin (NGAL), and interleukin-18 (IL-18); and as an effect of impaired reabsorption of the filtered load in the proximal tubule (NGAL, cystatin $\mathrm{C}$ ). Secretion of biomarkers from activated immune cells migrating into the tubular lumen may also be a source (NGAL, IL-18) (10).

Serum and urine KIM-1 performed significant superiority in early detection of AKI than others, especially within 24 hours, before serum creatinine increases, which made it possible to conduct prevention or treatment strategies at a very early stage of AKI(11).The characteristics of KIM-1 that may contribute to its utility as a biomarker of kidney injury include; the absence of KIM-1 expression in normal kidney, the markedly up-regulated expression in the injured proximal tubule, the persistent expression in proximal tubular epithelial cells until recovery from injury, the rapid and robust release of detectable soluble ectodomain into the urine upon tubular injury, and the ex vivo stability of the soluble KIM-1 ectodomain at room temperature. Serum and urine KIM-1 level is closely related to tissue KIM-1 and correlates with the severity of renal damage, so quantitation of urinary KIM-1 is likely to be a non-invasive and sensitive method for the evaluation of early kidney injury and even for monitoring the therapeutic effects of kidney injury. The Food and Drug Administration and European Medicines Evaluation Agency have included KIM-1 in the small list of kidney injury biomarkers that they had considered in the evaluation of kidney damage as part of their respective drug review processes of new drugs(12).

In the study of nephrotoxicity, urinary KIM-1 levels were severely increased earlier than the increases of blood urea nitrogen and plasma creatinine (13).Similar results were obtained in the ischemia-reperfusion (I/R) injury model (14).In the transplant biopsies, KIM-1 expression was reported as being able to diagnose early tubular injury that was not detectable by histological examination and KIM-1 also helped to distinguish acute tubular necrosis from other allograft dysfunction (15).

Therefore; this study was decided to measure serum kidney injury molecule-1 in patients with HRS to know if the criteria of ICA(2007) for diagnosis of HRS are sufficient to exclude intrinsic kidney injury, also to study the relation of serum KIM-1 to kidney function in those with and without possible intrinsic kidney injury.

\section{Patients and Methods}

This observational descriptive cross sectional study was carried out in hepatogastroentrology subunit of medical intensive care unit, Internal Medicine department and Medical Biochemistry department of Zagazig University from February 2015 to March 2016.

Out of 712 cirrhotic patients who were admitted to ICU, 103 patients had advanced cirrhoticascites with raised serum creatinine above $1.5 \mathrm{mg} / \mathrm{dl}$. Out of 103 patients, 2 patients died on the second day and 3 patients did not fulfil the criteria. So; 98 patients were included and classified into two types of HRS according to level and rising pattern of serum creatinine. Written Informed consent was taken from the all subjects after taking Institutional Review Board approval.

All patients of this study were subjected to full history,thorough clinical examination with exclusion of shock, sepsis, gastrointestinal bleeding, spontaneous bacterial peritonitis, and large volume paracentesis without albumin infusion.

Routine laboratory investigations were performed including urine analysis (glucose, RBCs, protein, $\mathrm{pH}$, bilirubin, leukocytes, crystals and sediment) by urine strips, $24 \mathrm{~h}$ urine protein, complete blood picture, $\mathrm{C}$ reactive protein (CRP), renal function tests (serum creatinine on the $1^{\text {st }}$ and $3^{\text {rd }}$ days of admission (16), eGFR and serum urea by colorimetric method (17)), liver function tests (serum bilirubin (total and direct), serum albumin, and serum alanine tranaminase (ALT) and aspartate transaminase (AST) by colorimetric method (18)), bleeding profile (Prothrombin time (PT), INR and Partial Thromboplastin Time (PTT)) and arterial blood gases $(\mathrm{ABG})$ and electrolytes $\left(\mathrm{pH}, \mathrm{PO}_{2}, \mathrm{PCO}_{2}, \mathrm{HCO}_{3}, \mathrm{Na}\right.$, $\mathrm{K})$, pelvi-abdominal ultrasonography, $\mathrm{ECG}$ and other investigations which was needed during ICU stay.

Specific investigationsincluded measurement of serum KIM-1 by enzyme-linked immunosorbent assay (ELISA) at time of admission (19)according to the manufacturer protocol produced by MyBioSourceMBS700484, San Diego, California, USA. The assay has high sensitivity $(0.043 \mathrm{ng} / \mathrm{ml})$ and excellent specificity for human KIM-1 with no cross-reactivity.

Statistical analysis; all data were analyzed using SPSS 15.0.Continuous variables were expressed as mean \pm SD and categorical variables were expressed as a number (percentage). Normally distributed data were analyzed using independent student $\mathrm{t}(\mathrm{t})$ test. Non-normally distributed data were analyzed using Mann-Whitney U (MW) test. Percent of categorical variables were compared using the Chi-square $\left(\chi^{2}\right)$ test. The Spearman's rank correlation coefficient was calculated to assess the correlations between serum KIM-1 and various study parameters. Receiver operating characteristic (ROC) curve analysis was used to identify optimal cut-off values of serum KIM-1 with maximum sensitivity and specificity. $\mathrm{P}$ value $<0.05$ was considered statistically significant (S), $p<0.005$ was considered highly significant (HS), and $\mathrm{p} \geq 0.05$ was considered non-significant (NS). 


\section{International Journal of Science and Research (IJSR) \\ ISSN (Online): 2319-7064 \\ Index Copernicus Value (2013): 6.14 | Impact Factor (2015): 6.391}

\section{Results}

This study included98 patients; according to thelevel at admission and pattern of rise of serum creatinine, we found 71 patients $(73.5 \%)$ of type 1 HRS and 27 patients $(26.5 \%)$ of type 2 HRS. 64 patients were males $(65.3 \%)$ and 34 patients were females $(34.7 \%)$ with mean age of $59.15 \pm 8.81$ years. There was no significant difference in age, sex or clinical data between the two groups of HRS. At admission; there was significant elevation in the mean \pm SD values of urine protein and serum creatinine. The mean $\pm \mathrm{SD}$ values of eGFR, ALT and AST were significantly decreased in in type1 HRS as compared to type 2 while there was no significant difference of mean $\pm \mathrm{SD}$ values of other routine laboratory parameters between the two types of HRS. Highly significant increase of serum KIM-1 level was found in type1 HRS as compared to type2 (table1). The best cutoff value for serum KIM-1 for the severity of AKI in HRS indicates that it is considered a valid marker with better positive than negative in prediction of intrinsic AKI among patients diagnosed with HRS (table 2). The percentage of possible intrinsic kidney injury was $76.1 \%$ in type 1 HRS and $24.9 \%$ in type2 (table 3). Regarding the correlation between serum KIM-1 and both clinical and laboratory data; significant positive correlation was found with urine protein and serum creatinine, while significant negative correlation was found with eGFR and no significant correlation was found with other study parameters(table4). In possible intrinsic AKI patients; a significant positive correlation was found with urine protein and serum creatinine, and a significant negative correlation with eGFR(table5). In patients without intrinsic AKI; a significant positive correlation with serum creatinine was found, while there was no significant correlation with other parameters.

\section{Discussion}

Current understanding of HRS suggests that it is a hemodynamically driven process without intrinsic renal damage; thus it is possible that some patients with HRS have a secondary insult of acute tubular necrosis (ATN). The absence of a diagnostic test linked to the biology of disease and nonspecific clinical criteria do not allow the clinician to simultaneously diagnose a patient with ATN and HRS, even though it is possible that multiple insults may explain a patient's clinical status (20).

Several issues remain to be addressed to clarify the role of new biomarkers of renal tubular damage in predicting the progression and prognosis of AKI, and in the differential diagnosis of the different types of AKI in patients with cirrhosis(21).

This study aimed to measure serum KIM-1 in patients with HRS diagnosed according to IAC criteria (2007) to know if this criteria is sufficient to exclude intrinsic kidney injury and to know the percentage of the intrinsic kidney injury in the two major types of HRS, also to study the relation of serum level of KIM-1 to kidney function parameter in those with and without possible intrinsic kidney injury.

The present study revealed that $72.9 \%$ of our patients with HRS belong to type1 and remaining $27.1 \%$ had type 2 and there was no significant difference between two types of HRS regarding sex, age, clinical and laboratory data except Child-Pugh score, serum creatinine, urine protein (but still below $500 \mathrm{mg} / \mathrm{dl}$ ) and serum KIM-1 which were significantly higher in type1 compared to type2, while eGFR, ALT, AST was significantly lower in type1 as compared to type2. Similar results was obtained by Licata et al.,(22) who compared type1 and type 2 HRS patients and showed no statistically significant differences between the two groups regarding age, sex, clinical and laboratory data except serum creatinine, creatinine clearance, and INR values. The significant difference between the two types in INR values in the study by Licata et al.(22)is more acceptable because the increase in INR value is consistent with the severity of liver failure in type1 with multi-organ failure rather than type2, while the significant difference between the two types in transaminases values in the present study were also acceptable because of the negative relationship between transaminases values and the advanced degree of cirrhosis because transaminases drop with fewer liver cells remaining to produce and release enzymes (23).

The present study showed that the best cutoff value for serum KIM-1 for the severity of AKI in HRS is $3.69 \mathrm{ng} / \mathrm{ml}$ with sensitivity of $88.6 \%$, specificity of $76.9 \%$, and AUC of $0.81 \%$. Similar results was obtained by Vijayasimha et al.(24) who suggested that the best cutoff value for KIM-1 to predict AKI was $4.5 \mathrm{ng} / \mathrm{ml}$, with diagnostic sensitivity $89 \%$ and specificity $81 \%$.

In this study, patients with serum KIM-1 levels higher than the cutoff value were considered to have possible intrinsic kidney injury, the percentage of intrinsic kidney injury in type 1 was $75.6 \%$, and in type 2 is $24.4 \%$. Barreto et al. (25)used KIM-1 for assessment of AKI in cirrhosis, their study showed increasing values of the biomarker in HRS and intrinsic AKI than that of prerenal AKI in cirrhotic patients and they suggested the existence of an overexpression of KIM-1 in the kidneys of patients with cirrhosis.

In this study, there was significant positive correlation between serum KIM-1 and each of urine protein, serum creatinine, Child-Pugh score, but negative correlation with eGFR in all HRS patients while there was significant positive correlation between serum KIM-1 and each of urine protein and srum creatinine, and negative correlation between serum KIM-1 and eGFR in those with possible intrinsic kidney injury. This was consistent with study done by Song et al.,(26)on KIM-1 expression with allograft rejection which showed significant positive correlation between KIM-1 and serum creatinine level, also similar results was obtained in study done by Xueet al.,(27) on diagnostic performance of KIM-1 for AKI in an obstructive nephropathy patient, showed that KIM-1 content positively correlated with serum creatinine, but negatively correlated with eGFR, this results are explanation of more KIM-1 expression with renal damage, and therefore rising serum creatinine and decrease in eGFR. In the other hand, a study done by Timmeren et al.(28) on tubular KIM-1 in human renal disease showed no significant correlation between KIM-1 and proteinuria. Our conclusion that there is a correlation between KIM-1 and proteinuria in the present

\section{Volume 5 Issue 7, July 2016}




\section{International Journal of Science and Research (IJSR) \\ ISSN (Online): 2319-7064}

Index Copernicus Value (2013): 6.14 | Impact Factor (2015): 6.391

study is the best theoretically because proteinuria increases more with tubular damage.

The higher level of serum KIM-1 in HRS might be due to the wide overlapping between HRS and co-existing other intrinsic AKI conditions, especially tubular injury such as ATN and bilirubin nephropathy.

The current diagnostic criteria for HRS do not rule out the possibility of renal parenchymal damage (29). A study done by Salerno et al.,(30) showed that current diagnostic criteria for HRS allow for a correct diagnosis in only two thirds of cases. From the above studies, IAC is considered sufficient for diagnosing HRS status, but not sufficient for excluding presence of other insults with the condition.

HRS patients with intrinsic kidney injury in this study were considered type3 HRS which means coexistent kidney disease (acute or chronic) and HRS. A cirrhotic patient with long-standing diabetic nephropathy, obstructive renal disease, or chronic glomerulonephritis can develop HRS from a precipitating event or worsening liver failure (4).

\section{Conclusion}

IAC (2007) did not rule out the possibility of intrinsic kidney injury especially the tubular injury. Using renal biomarkers at certain cut off value is very useful for differentiation between HRS and other intrinsic kidney injury conditions. Serum KIM-1 may be considered a valid marker with better sensitivity than specificity. The percentage of intrinsic kidney injury is very high in type 1 HRS than in type 2 in this study and can be classified as type3.

\section{Recommendations}

We recommend that; criteria of IAC (2007) must be revised for exclusion of other intrinsic kidney injury conditions, further studies are needed to appreciate the prognostic significance of early elevation of KIM-1 levels instead of depending on rising serum creatinine to improve the outcome by early therapeutic intervention, and larger scale study are needed to determine accurate cutoff value for serum KIM-1.

\section{Conflict of Interests}

There is no conflict of interests.

\section{References}

[1] Fagundes C, Ginès P. Hepatorenal syndrome: A severe, but treatable, cause of kidney failure in cirrhosis. Am J Kidney Dis. 2012; 59:874-85.

[2] Fasolato S, Angeli P, Dallagnese L, Maresio G, Zola E, Mazza E et al.,Renalfailureandbacterial infections in patients with cirrhosis: epidemiologyandclinicalfeatures.Hepatology.2007;45:2 23-229.

[3] Salerno F, Gerbes A, Gines P, Wong F, Arroyo $\mathrm{V}$. Diagnosis, prevention and treatment of hepatorenal syndrome in cirrhosis. Postgrad Med J. 2008; 84(998):662-70.

[4] Munoz SJ. The hepatorenal syndrome. Med Clin North Am. 2008; 92(4):813-837.

[5] Angeli P, Ginès P, Wong F, Bernardi M, Boyer TD, Gerbes A et al.Diagnosis and management of acute kidney injury in patientswithcirrhosis: revised consensus recommendationsoftheInternationalClub of Ascites. J Hepatol. 2015; 62: 968-974.

[6] de Geus HR, Betjes MG, Bakker J. Biomarkers for the prediction of acute kidney injury: a narrative review on current status and future challenges. Clin Kidney J. 2012; 5:102-108.

[7] DevarajanP.Emergingbiomarkersofacutekidneyinjury.C ontribNephrol.2007; 156:203-212.

[8] Wong F, Nadim MK, Kellum JA,Salerno F, Bellomo $\mathrm{R}$, Gerbes A et al. Working Party proposal for a revised classification system of renal dysfunction in patients with cirrhosis. Gut. 2011; 60:702-709.

[9] Schiffl H, Lang SM. Earlier diagnosis of acute kidney injury in critically ill patients by novelbiomarkers: Moving from supportive care to targetedrenoprotection? OA Critical Care. 2013; 1(1):5.

[10] Märtensson J, Bell $\mathrm{M}$, Oldner $\mathrm{A}$, Xu S, Venge $\mathrm{P}$, Martling CR. Neutrophil gelatinase-associated lipocalin in adult septic patients with and without acute kidney injury.Intensive Care Med. 2010 Aug; 36(8):1333-40.

[11] Liangos O, Tighiouart H, Perianayagam MC, Kolyada A, Han WK, Wald R et al. Comparative analysis of urinary biomarkers for early detection of acute kidney injury following cardiopulmonary bypass.Biomarkers. 2009; 14(6):423-31.

[12] Bonventre JV.Kidney injury molecule-1 (KIM-1): a urinary biomarker and much more.Nephrol Dial Transplant. 2009; 24(11):3265-8.

[13] Prozialeck WC, Edwards JR, Lamar PC, Liu J, Vaidya VS, Bonventre JV. Expression of kidney injury molecule-1 (Kim-1) in relation to necrosis and apoptosis during the early stages of $\mathrm{Cd}$-induced proximal tubule injury. Toxicol Appl Pharmacol. 2009; 238(3):306-14.

[14] Coca SG, Yalavarthy R, Concato J, Parikh CR.Biomarkers for the diagnosis and risk stratification of acute kidney injury: a systematic review.Kidney Int. 2008; 73(9):1008-16.

[15]Zhang PL, Rothblum LI, Han WK, Blasick TM, Potdar S, Bonventre JV. Kidney injury molecule-1 expression in transplant biopsies is a sensitive measure of cell injury.Kidney Int. 2008; 73(5):608-14.

[16] Harry H, Abraham R. Estimation of Creatinine by the Jaffe Reaction: A Comparison of Three Methods. Clinic Chem. 1968, 14: 222- 238.

[17] Fawcett JK, Scott JE. A rapid and precise method for the determination of urea.J ClinPathol. 1960; 13:156-9.

[18] Thomas L. Alanine aminotransferase (ALT), Aspartate aminotransferase (AST). In: Thomas L, editor. Clinical Laboratory Diagnostics. 1st ed. Frankfurt: TH-Books Verlagsgesellschaft; 1998. p. 55-65.

[19] Shalini C, Takeisha F, and Gordon FK.Assay Validation for KIM-1: human urinary renal dysfunction biomarker.Int J Biol Sci. 2009; 5(2): 128-134. 


\section{International Journal of Science and Research (IJSR) \\ ISSN (Online): 2319-7064 \\ Index Copernicus Value (2013): 6.14 | Impact Factor (2015): 6.391}

[20] Allegretti AS, Ortiz G, Wenger J, Deferio JJ, Wibecan $\mathrm{J}$, Kalim $\mathrm{S}$ et al.Prognosis of Acute Kidney Injury and Hepatorenal Syndrome in Patients with Cirrhosis: A Prospective Cohort Study.Int J Nephrol. 2015;139:1-9.

[21] Belcher JM, Sanyal AJ, Peixoto AJ, Perazella MA, Lim J, Thiessen-Philbrook

Hetal.Kidney biomarkers and differential

diagnosis of patients with cirrhosis and acutekidneyinjury. Hepatology. 2014 Aug; 60(2):622-32.

[22] Licata A, Maida M, Bonaccorso A, Macaluso FS, Cappello M, CraxìA et al. Clinical course and prognostic factors of hepatorenal syndrome: A retrospective single-center cohort study. World J Hepatol. 2013; 5(12):685-91.

[23] Schubert F. Liver Enzymes \& Cirrhosis.In: Clinical Diagnosis and Management byLaboratory Methods. John Bernard Henry, 19th Edition. W B Saunders Co.1996; 500-522.

[24] Vijayasimha M, Vijaya Padma V, Saroj Kumar Das Mujumdar, P Satyanarayana VV.Kidney injury molecule-1: a urinary biomarker for contrast induced acute kidney injury.Advances in Life Science and Technology.2013;15; 33-38.

[25] Barreto RC. Fagundes R, Moreira E, Rodriguez R, Cela E,Solà I et al. Urinary Kidney Injury Molecule-1 (Kim-1) In the Assessment of Acute Kidney Injury in
Patients with Cirrhosis.Journal of Hepatology. 2013; 58: 409-566.

[26] Song L, Xue L, Yu J, Zhao J, Zhang W, Fu Y.Kidney injury molecule-1 expression is closely associated with renal allograft damage. Bosn $\mathrm{J}$ Basic Med Sci. 2013; 13(3):170-4.

[27] XueW, XieY, WangQ, XuW, MouS, NiZ.Diagnostic pe rformance of urinary kidney injury molecule-1 and neutrophil gelatinase-associated lipocal in for acute kidney injury in an obstructive nephropathy patient. Nephrology(Carlton).2014;19(4):186-94.

[28] van Timmeren MM, van den Heuvel MC, Bailly V, Bakker SJ, van Goor H, Stegeman CA.Tubular kidney injury molecule-1 (KIM-1) in human renal disease.J Pathol. 2007 Jun; 212(2):209-17.

[29] Trawalé JM, Paradis V, Rautou PE, Francoz C, Escolano $\mathrm{S}$, Sallée $\mathrm{M}$ et al. The spectrum of renal lesions in patients with cirrhosis: A clinicopathological study.Liver Int. 2010 May; 30(5):725-32.

[30] Salerno F, Cazzaniga M, Merli M, Spinzi G, Saibeni $\mathrm{S}$, SalmiA et al. Association of the Hospital Gastroenterologists (AIGO) investigators. Diagnosis, treatment and survival of patients with hepatorenalsyndrome: survey on daily medical practice. J Hepatol. 2011; 55(6):1241-8.

Table 1: Comparison of the mean $\pm \mathrm{SD}$ of age, sex, some clinical data and laboratory data between the two types of HRS

\begin{tabular}{|c|c|c|c|c|c|c|}
\hline Variable & \multicolumn{2}{|c|}{ Type1 $(\mathrm{n}=71)$} & \multicolumn{2}{|c|}{ Type2 $(n=27)$} & \multirow{2}{*}{$\frac{\text { Test }}{\chi^{2}}$} & \multirow[t]{2}{*}{$P$ value } \\
\hline Gender & No & $\%$ & No & $\%$ & & \\
\hline Male & 49 & 69.0 & 15 & 55.6 & 2.34 & $0.13 \mathrm{NS}$ \\
\hline \multirow[t]{2}{*}{ Female } & 22 & 31.0 & 12 & 44.4 & & \\
\hline & \multicolumn{2}{|c|}{ Mean \pm SD } & \multicolumn{2}{|c|}{ Mean \pm SD } & $\mathbf{T}$ & \\
\hline Age (years) & \multicolumn{2}{|c|}{$59.54 \pm 9.21$} & \multicolumn{2}{|c|}{$58.08 \pm 7.88$} & 0.51 & $0.61 \mathrm{NS}$ \\
\hline Pulse (b/m) & \multicolumn{2}{|c|}{$78.83 \pm 5.04$} & \multicolumn{2}{|c|}{$78.85 \pm 6.01$} & 0.01 & $0.99 \mathrm{NS}$ \\
\hline Systolic BP (n & \multicolumn{2}{|c|}{$94.57 \pm 5.2$} & \multicolumn{2}{|c|}{$94.23 \pm 4.94$} & 0.20 & $0.84 \mathrm{NS}$ \\
\hline Diastolic BP (I & \multicolumn{2}{|c|}{$64.86 \pm 5.07$} & \multicolumn{2}{|c|}{$66.15 \pm 5.06$} & 0.79 & $0.44 \mathrm{NS}$ \\
\hline 24h protein (mg/day) & \multicolumn{2}{|c|}{$317.6 \pm 82.61$} & $242 \pm$ & 55.2 & 3.05 & $<0.01 \mathrm{HS}$ \\
\hline Urea(mg/dl) & \multicolumn{2}{|c|}{$62.43 \pm 9.46$} & \multicolumn{2}{|c|}{$64.46 \pm 13.42$} & 0.59 & $0.56 \mathrm{NS}$ \\
\hline $\mathrm{Hb}(\mathrm{g} / \mathrm{dl})$ & \multicolumn{2}{|c|}{$9.14 \pm 0.89$} & \multicolumn{2}{|c|}{$9.01 \pm 0.75$} & 0.48 & $0.64 \mathrm{NS}$ \\
\hline $\operatorname{TLC}\left(\times 10^{3} / \mathrm{L}\right)$ & \multicolumn{2}{|c|}{$6.94 \pm 2.16$} & \multicolumn{2}{|c|}{$6.81 \pm 1.77$} & 0.20 & $0.84 \mathrm{NS}$ \\
\hline Platelet $\left(\mathrm{x} 10^{3} / \mathrm{L}\right)$ & \multicolumn{2}{|c|}{$87.22 \pm 16.73$} & \multicolumn{2}{|c|}{$85.38 \pm 14.93$} & 0.35 & $0.73 \mathrm{NS}$ \\
\hline Serum albumin (g/dl) & \multicolumn{2}{|c|}{$2.25 \pm 0.30$} & \multicolumn{2}{|c|}{$2.41 \pm 0.26$} & 1.72 & $0.09 \mathrm{NS}$ \\
\hline INR & \multicolumn{2}{|c|}{$2.05 \pm 0.38$} & \multicolumn{2}{|c|}{$2.05 \pm 0.33$} & 0.022 & $0.98 \mathrm{NS}$ \\
\hline $\operatorname{ALT}(\mathrm{U} / \mathrm{L})$ & \multicolumn{2}{|c|}{$34.31 \pm 9.18$} & \multicolumn{2}{|c|}{$46.92 \pm 15.45$} & 3.48 & $<0.01 \mathrm{HS}$ \\
\hline AST (U/L) & \multicolumn{2}{|c|}{$45.23 \pm 9.21$} & \multicolumn{2}{|c|}{$58.54 \pm 18.35$} & 3.34 & $<0.01 \mathrm{HS}$ \\
\hline Total biliru & \multicolumn{2}{|c|}{$4.1 \pm 1.99$} & \multicolumn{2}{|c|}{$4.54 \pm 3.4$} & 0.60 & $0.54 \mathrm{NS}$ \\
\hline KIM-1 (ng/ml) & 6.3 & \pm 3.03 & 4.11 & $=0.91$ & 88.5 & $<0.01 \mathrm{HS}$ \\
\hline & Me & \pm SD & Me: & \pm SD & MW & \\
\hline urine RBCs: RBCS/HPF & 12.1 & \pm 7.17 & 11.62 & \pm 7.17 & 218.5 & $0.84 \mathrm{NS}$ \\
\hline Serum creatinine (mg/dl) & 3.3 & $=0.52$ & 2.02 & 0.25 & 8.82 & $<0.01 \mathrm{HS}$ \\
\hline eGFR $\left(\mathrm{ml} / \mathrm{min} / 1.73 \mathrm{~m}^{2}\right)$ & 20. & \pm 4.59 & 37.1 & \pm 6.61 & 10 & $<0.01 \mathrm{HS}$ \\
\hline
\end{tabular}

NS: non significant

HS: highly significant

Table 2: Accuracy of KIM-1 in diagnosis of intrinsic kidney injury

\begin{tabular}{|c|c|c|c|c|c|c|c|}
\hline Cutoff & AUC & Sens. & Spec. & + PV & -PV & Accuracy & p-value \\
\hline 3.69 & 0.81 & 88.6 & 76.9 & 91.2 & 71.4 & 85.4 & $0.001 \mathrm{HS}$ \\
\hline
\end{tabular}

Table 3: Frequency of possible intrinsic acute kidney injury in type-1\&type-2 HRS according to cut off value of serum KIM-

\begin{tabular}{|c|c|c|}
\hline \multirow{2}{*}{ Types of HRS } & \multicolumn{2}{|c|}{1} \\
\cline { 2 - 3 } & intrinsic kidney injury \\
\cline { 2 - 3 } & No & $\%$ \\
\hline Type1 & 54 cases & 76.1 \\
\hline Type2 & 7 cases & 24.9 \\
\hline
\end{tabular}

Volume 5 Issue 7, July 2016 www.ijsr.net

Licensed Under Creative Commons Attribution CC BY 


\section{International Journal of Science and Research (IJSR) \\ ISSN (Online): 2319-7064}

Index Copernicus Value (2013): 6.14 | Impact Factor (2015): 6.391

able 4: Correlation coefficient between serum KIM-1 and the clinical and lab data in all studied subjects of HRS

NS: non significant

\begin{tabular}{|c|c|c|}
\hline Variable & $\mathrm{r}$ & $\mathrm{P}$ \\
\hline Age (years) & -0.06 & $0.73 \mathrm{NS}$ \\
\hline Pulse: $b / m$ & -0.05 & $0.74 \mathrm{NS}$ \\
\hline Systolic blood pressure mmHg & 0.18 & $0.22 \mathrm{NS}$ \\
\hline Diastolic blood pressure $\mathrm{mmHg}$ & 0.21 & $0.15 \mathrm{NS}$ \\
\hline 24h urine Protein mg/day & 0.46 & $0.001 \mathrm{HS}$ \\
\hline RBCs in urine RBCS/HPF & -0.05 & $0.76 \mathrm{NS}$ \\
\hline eGFR $\mathrm{ml} / \mathrm{min} / 1.73 \mathrm{~m}^{2}$ & -0.92 & 0.003 HS \\
\hline Urea mg/Dl & 0.18 & $0.22 \mathrm{NS}$ \\
\hline Creatinine $\mathrm{mg} / \mathrm{dL}$ & 0.46 & 0.001 HS \\
\hline $\mathrm{Hb}$ g/dl & 0.08 & $0.61 \mathrm{NS}$ \\
\hline $\operatorname{TLC10}^{9} / \mathrm{L}$ & 0.087 & $0.96 \mathrm{NS}$ \\
\hline Platelet10 $9 / \mathrm{L}$ & 0.054 & $0.21 \mathrm{NS}$ \\
\hline S.albumin g/dl & 0.031 & $0.76 \mathrm{NS}$ \\
\hline INR & -0.09 & $0.91 \mathrm{NS}$ \\
\hline $\mathbf{A L T} \mathbf{u} / \mathbf{l}$ & -0.14 & $0.35 \mathrm{NS}$ \\
\hline AST u/l & -0.14 & $0.34 \mathrm{NS}$ \\
\hline Total bilirubin mg/dL & 0.23 & $0.97 \mathrm{NS}$ \\
\hline
\end{tabular}

Table 5: Correlation coefficient between serum KIM-1 and laboratory data in patients with serum KIM-1 above the cutoff value

\begin{tabular}{|c|c|c|}
\hline \multirow[t]{2}{*}{ Variable } & \multicolumn{2}{|c|}{ Intrinsic kidney injury patients $(n=61)$} \\
\hline & $\mathrm{r}$ & $\mathrm{P}$ \\
\hline 24h urine protein $\mathrm{mg} / \mathrm{day}$ & 0.43 & $0.005 \mathrm{~S}$ \\
\hline RBCs in urine RBCS/HPF & -0.003 & $0.98 \mathrm{NS}$ \\
\hline eGFR $\mathrm{ml} / \mathrm{min} / 1.73 \mathrm{~m}^{2}$ & -0.91 & $0.01 \mathrm{~S}$ \\
\hline Urea $\mathbf{m g} / \mathrm{dL}$ & 0.24 & $0.12 \mathrm{NS}$ \\
\hline Creatinine mg/dL & 0.42 & $0.006 \mathrm{~S}$ \\
\hline
\end{tabular}

NS: non significantS: significant

Volume 5 Issue 7, July 2016

www.ijsr.net

Licensed Under Creative Commons Attribution CC BY 